\title{
Adoption of Mobile Assisted Language Learning (MALL) in Saudi Arabian EFL Classrooms
}

\author{
Sulaiman Alnujaidi \\ Department of English, College of Languages and Translation, Imam Muhammad Ibn Saud Islamic University (IMSIU), \\ Riyadh, Saudi Arabia
}

\begin{abstract}
This study aimed to examine EFL teachers' concerns about the adoption of Mobile Assisted Language Learning (MALL) in Saudi Arabia. The Concerns-Based Adoption Model (CBAM) was used to analyze the participants' stages of concern (SoC) about MALL. The study also investigated whether some specific demographic and technographic variables (gender, age, teaching experience, and professional development) had any statistically significant effect on EFL teachers' stages of concern about MALL. The participants in this study were (130) Saudi EFL public school teachers. The results revealed that the participants had high concerns at the Informational, Personal, and Management stages and minimal concerns at the Awareness, Refocusing, Collaboration, and Consequence stages. The MANOVA analysis revealed no significant difference among EFL teachers in terms of their MALL stages of concerns in relation to their gender, age, and teaching experience. Such findings indicate that Saudi EFL teachers' gender, age, and teaching experience have no effect on their concerns about using and implementing MALL. However, The MANOVA analysis yielded a significant difference among EFL teachers in terms of their MALL stages of concerns in relation to their professional development. These results entail that Saudi EFL teachers' professional development has a significant effect on their concerns about MALL. The study concluded that technology-related professional development could help decrease teachers' self-concerns and increase their impact-concerns. The study recommended providing EFL teachers with technology-related professional development to ensure successful MALL adoption.
\end{abstract}

Index Terms-English as a Foreign Language (EFL), Mobile Assisted Language Learning (MALL), ConcernsBased Adoption Model (CBAM), Stages of Concerns (SoC)

\section{INTRODUCTION}

Some researchers asserted that we are moving from the "Age of the PC" to the "Age of Mobilism" in which "classrooms move from 'I Teach' teacher-centric pedagogy to 'We Learn' pedagogy where the teacher learns along with the student, mastering content and practicing the key $21^{\text {st }}$ century skills" (Norris \& Soloway, 2011, p.3). In the same vein, Prensky (2001) described today's students as "digital natives" who spend most of their time using mobile phones, videogames, and digital players. The exponential growth of information and communication technologies has reshaped the EFL learning and teaching landscape. To cope up with this rapid change, EFL research has gone through three major phases: (1) Computer Assisted Language Learning (CALL), (2) Web Assisted Language Learning (WALL), and (3) Mobile Assisted Language Learning (MALL). While there is an abundance of literature examining the adoption and integration of CALL and WALL, research on Mobile Assisted Language Learning (MALL) is still in its infancy (Kukulska-Hulme \& Shield, 2008). Current research on MALL covers a variety of topics including learning theories, pedagogical approaches, instructional models, curriculum design, teachers' and students' attitudes, and technical requirements. Investigating teachers' stages of concern and their levels of use of MALL is of paramount significance to ensure the effective adoption and integration of new technologies into EFL classrooms.

\section{A. Statement of the Problem}

Despite the growing research on the positive outcomes of integrating mobile technologies into EFL teaching and learning, little research has investigated the stages of concern about MALL in Saudi Arabian EFL classrooms. This study attempts to fill this research gap and contributes to existing research by examining EFL teachers' stages of concern (SoC) and analyzing the factors that might impact MALL adoption among EFL teachers through investigating whether EFL teachers' gender, age, teaching experience, and professional development have any significant effect on their stages of concern about MALL.

\section{B. Purpose of the Study}

Drawing on the above-mentioned research gap, this study attempts to answer the following research questions:

1. What are EFL teachers' stages of concern (SoC) about Mobile Assisted Language Learning (MALL)?

2. Do gender, age, teaching experience, and professional development have any statistically significant effect on teachers' stages of concern $(\mathrm{SoC})$ about MALL? This question is divided into four sub-questions: 
a. Is there a statistically significant difference among EFL teachers in terms of their stages of concern about MALL based on their gender?

b. Is there a statistically significant difference among EFL teachers in terms of their stages of concern about MALL based on their age?

c. Is there a statistically significant difference among EFL teachers in terms of their stages of concern about MALL based on their teaching experience?

d. Is there a statistically significant difference among EFL teachers in terms of their stages of concern about MALL based on their professional development?

\section{Significance of the Study}

The findings of this study contribute valuable information for researchers, curriculum designers, and policy makers to understand the stages of concerns about MALL among EFL teachers in order to provide them with appropriate professional development activities, effective instructional methods, and interactive technology-based curricula and programs. Investigating the factors that influence teachers' stages of concerns about MALL may help in understanding the adoption patterns, implementation processes, and expected challenges concerning mobile assisted language learning. It is hoped that the findings of this study inspire professionals and institutions to provide appropriate professional development resources and programs that facilitate successful adoption and integration of MALL.

\section{LITERATURE REVIEW}

\section{A. Definition and Features of Mobile Assisted Language Learning (MALL)}

The rapidly-growing information and communication technologies have reshaped learning from D-Learning (distance) to E-Learning (electronic) to M-Learning (mobile) (Basak, et al., 2018; Kim, 2012; Korucu \& Alkan, 2011; Ozuorcun \& Tabak, 2012). M-Learning is defined as "any educational provision where the sole or dominant technologies are handheld or palmtop devices"(Traxler, 2005, p. 262). This new kind of learning takes account of "the mobility of technology, mobility of learners and mobility of learning" (El-Hussein \& Cronje, 2010, p. 20). M-Learning is not constrained by time, place, and space; in addition, students are not restricted by specific age, gender, or geography to participate in learning opportunities (Behera, 2013). The educational potential of M-Learning can radically change the learning environment because it offers more choice in when, where, and how teachers teach and students learn (Walsh \& Shaheen, 2013).

As the movement from D-Learning to E-Learning to M-Learning has taken place over the past few years, a similar transition in second language teaching has also shifted from Computer Assisted Language Learning (CALL) to Web Assisted Language Learning (WALL) to Mobile Assisted Language Learning (MALL). As a subset of both M-Learning and CALL, MALL is considered as an approach to language learning that utilizes mobile devices such as mobile phones (e.g. iPhone), tablets (e.g. iPad.), MP3/MP4 players (e.g. iPods), and PDAs (e.g. Blackberry). (Valarmathi, 2011). What makes MALL different from CALL is its portable devices that provide learners with continuous access and constant interaction anywhere, anytime according to their contexts (Kukulska-Hulme and Shield, 2008). Some of the most distinctive features which mobile technologies bring to the language learning context are mobility and portability (Kukulska-Hulme \& Shield, 2008); accessibility, affordability, and feasibility (Zurita \& Nussbaum, 2004); individuality, connectivity, and interactivity (Lan et al., 2007); inventiveness of knowledge acquaintance and integration of instructional content (Yedla, 2013).

\section{B. The Impact of MALL on EFL Learning}

Much of the research conducted on MALL focused on the impact of using mobile devices on acquiring language skills. Alemi et al. (2012) employed a mobile-based SMS vocabulary program for university students and reported a significantly better vocabulary retention by participants. Amer (2010) developed a mobile-based application for learning idiomatic expressions and collocations and found a significant correlation between learners' use of the application and their scores on the quizzes. Demouy \& Kukulska-Hulme (2010) investigated students' experiences when accessing listening and speaking activities on their own portable devices (mobile phones, iPods, and MP3 players) and indicated that the use of those devices improved students' listening and speaking skills. Chang \& Hsu (2011) developed a PDA-based system to support EFL students' reading comprehension through providing them with reading-assisting functions of instant translation and annotation modes. The study concluded that the system significantly contributed to enhancing EFL learners in reading comprehension. Anaraki (2009) designed and developed a mobile flash-based learning system and reported a significant impact of the system on students' pronunciation, listening, and conversation skills. Facer, Abdous, \& Camarena (2009) investigated the impact of academic podcasting on students' learning outcomes and discovered that podcasts helped students improve their listening, speaking, reading, and writing skills, as well as increase their knowledge of vocabulary and grammar.

\section{The Concerns-based Adoption Model (CBAM)}

The Concern-Based Adoption Model (CBAM) is a conceptual framework that provides tools and techniques for describing, facilitating, and measuring the implementation process of an innovation (Hall et al., 1973). According to 
Straub (2009), the CBAM provides "a developmental perspective on how an individual's concerns influence his or her integration of an innovation." (p. 632). The CBAM has three diagnostic dimensions (Figure 1) for guiding and assessing the adoption process: (1) Innovation Configuration (IC); (2) Stages of Concern (SoC); and (3) Levels of Use (LoU). For the scope of this study, only the Stages of Concern (Soc) component will be utlizied to determine EFL teachers' concerns about the adoption of MALL.

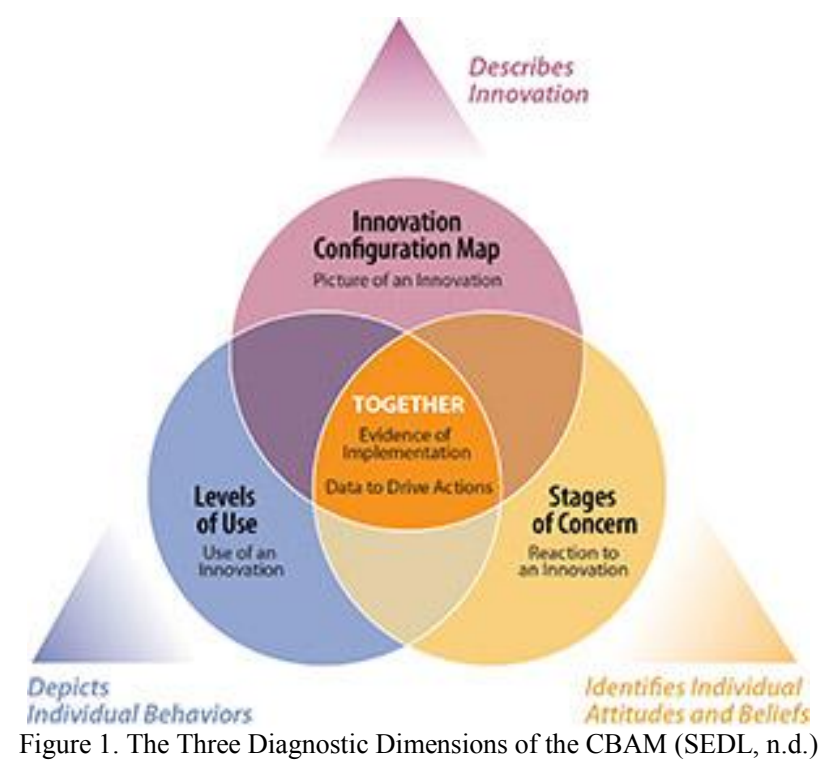

Stages of Concern (SoC) is a diagnostic framework for describing and analyzing people's feelings and concerns about an innovation. It focuses on individuals' perceptions and attitudes rather than behaviors and actions toward an innovation. When adopting an innovation, individuals go through a change process. If their concerns are considered, their adoption of the innovation will be more successful (Hall \& Hord, 1987). An Innovation refers to a new strategy, program, or practice. Concerns refer to the categorization of expressions stated by the users related to their use of the innovation. Stages of Concern are a developmental progression of these concerns. (George et al., 2006, p. 7).

Hall \& Hord (1987) proposed seven stages of concern (SoC) that individuals go through in their process of change when adopting an innovation as follows:

- Stage (0) Awareness: is a stage in which individuals have no knowledge/concern about or involvement with the innovation.

- Stage (1) Informational: is a stage in which individuals show a general awareness of and positive interest in the innovation. Particular attention in this stage is focused on the innovation's characteristics, requirements, and effects.

- Stage (2) Personal: is a stage in which individuals are uncertain about the demands of the innovation, their inadequacy to meet those demands, and their role with the innovation. Issues reflected in this stage include potential conflicts with existing structure, personal commitment, and financial implications.

- Stage (3) Management: is a stage in which individuals focus their attention on the processes and tasks of using the innovation and the best use of information and resources. Particular attention in this stage is centered on organization, management, scheduling, and time demands.

- Stage (4) Consequence: is a stage in which individuals focus their attention on the impact of the innovation on students. Concerns reflected in this stage include the relevance of the innovation for students, evaluation of student's outcomes, and changes needed to increase students' outcomes.

- Stage (5) Collaboration: is a stage in which individuals focus their attention on coordinating and cooperating with others regarding the use of the innovation.

- Stage (6) Refocusing: is a stage in which individuals focus their attention on exploring other ways and alternatives to use the innovation.

\section{The Relationship between the Stages of Concern (SoC) and Innovation Adoption}

The Stages of Concern ( $\mathrm{SoC}$ ) framework has been extensively used in previous studies as a frame of reference to examine and measure users' concerns about innovation adoption. According to Schoepp (2002), a successful implementation of an educational innovation is largely dependent on teachers' concerns about that innovation; and for technology integration to be successful and effective, the concerns of teachers must be highly considered. Using the SoC framework, Watkins (2014) examined the relationship between teachers' stages of concern and technology integration including specific demographic variables and reported a significant relationship between teachers' stages of concern about technology integration and some specific demographic variables, as well as a significant relationship 
between teachers' levels of technology integration and some specific demographic variables. Goktalay (2013) investigated faculty members' stages of concern with regard to the adoption of social media technology and found a strong relationship between their stages of concern and their levels of use of social media. The study also revealed that the lack of faculty professional development and the lack of support activities were among the main barriers that hinder the adoption of social media technology in the classroom. Ball (2014) explored faculty concerns toward implementing mobile technology devices in the classroom and found that age, gender, and teaching experience did not have a significant difference on faculty concerns toward using mobile technology devices in the classroom. Chen (2017) investigated the perceptions and acceptance of university EFL instructors and students toward mobile learning and indicated that both instructors and students had a positive perception toward M-Learning in and out of the classroom, had a high acceptance level of M-Learning for EFL teaching and learning, and had a positive relationship between their perceptions and their acceptance. Schoepp (2002) examined the relationships between EFL teachers' technological use, concerns, and perceived barriers toward technology integration and discovered a very high correlation between teachers' stages of concern and their levels of use of technology. The study reported no significant difference between gender and computer use and no significant difference between their teaching experience and their stages of concern. Atkins \& Vasu (2000) studied teachers' concerns, knowledge, and use of technology and revealed significant relationships between teachers' stages of concern and level of technology integration, hours of technology training, and age.

\section{METHOD}

\section{A. Research Design}

This study employed a quantitative research design to examine teachers' concerns about the adoption of MALL and to investigate whether some specific demographic and technographic variables (gender, age, teaching experience, and professional development) have any statistically significant effect on EFL teachers' stages of concern about MALL.

\section{B. Instrument and Data Collection}

The Stages of Concern Questionnaire (SoCQ) was used to examine the participants' concerns about the adoption of mobile assisted language learning. The SoCQ is a self-report, 35-item instrument designed to assess participants' stages of concern about adopting an innovation (George et al., 2006). The SoCQ measures seven stages of concern that reflect three dimensions: self (awareness, informational, and personal); task (management); and impact (consequence, collaboration, and refocusing). Each stage was expressed as follows: Stage 0: Awareness (e.g. "I am not concerned about the innovation"); Stage 1: Informal (e.g. "I'd like to know more about the innovation"); Stage 2: Personal (e.g. "How will using the innovation affect me?"); Stage 3: Management (e.g. "How much time do I need to get my materials ready when using the innovation?"); Stage 4: Consequence (e.g. "How will my use of the innovation affect my students"); Stage 5: Collaboration (e.g. "I'd like to coordinate my use of the innovation with other colleagues"); Stage 6: Refocusing (e.g. "I have some ideas about something that would work even better") (George et al., 2006).

The authors of CBAM indicated that scoring the SoCQ requires calculating raw scores for each stage, locating the percentile score for each stage, and plotting the results on the stages of concern profile chart. The percentile score represents the relative intensity of concern at each stage. The higher the score, the more intense the concerns are at that stage. The lower the score, the less intense the concerns at that stage (George et al., 2006).

\section{Validity \& Reliability}

The Stages of Concern Questionnaire (SoCQ) has been extensively used in research studies, dissertations, and programs and its validity and reliability have been tested on various studies. George et al. (2006) asserted that the validity of the SoCQ scores was established by inter-correlation matrices, results of interview data, and confirmation of expected group differences and changes over time. George et al. (2006) also reported high reliability scores of SoCQ with alpha coefficients ranging from .64 to .83 and test-retest correlations ranging from .65 to .86 .

For the scope of this study, the reliability of the instrument was measured again and yielded stable and consistent results (Table 1) which proved the instrument to be valid and reliable for measuring the SoCQ of the participants in this study.

TABLE 1

CRONBACH'S ALPHA RELIABILITY COEFFICIENTS FOR THE SOCQ INSTRUMENT

\begin{tabular}{llc} 
& CRONBACH'S ALPHA RELIABILITY COEFFICIENTS FOR THE SOCQ INSTRUMENT & Alpha \\
\hline Stage & Number of Items & .60 \\
\hline Stage (0) Awareness & 5 & .76 \\
Stage (1) Informational & 5 & .79 \\
Stage (2) Personal & 5 & .75 \\
Stage (3) Management & 5 & .76 \\
Stage (4) Consequence & 5 & .80 \\
Stage (5) Collaboration & 5 & .71 \\
Stage (6) Refocusing & 5 & .71 \\
\hline
\end{tabular}




\section{Data Collection and Analysis}

Data was collected from a sample of (130) Saudi EFL teachers. The participants were full-time teachers in Saudi public schools. The participants came from several cities in Saudi Arabia, namely, Riyadh, Jeddah, Dammam, Buraidah, Abha, and Arar. The SoCQ was distributed and collected electronically (web-based) and results obtained in this study were analyzed using SPSS Statistics.

For the scope of this study, four independent variables and seven dependent variables were investigated. The independent variables were gender, age, teaching experience, and professional development. Gender included two groups: male and female. Age was divided into three groups: 20-38 years old, 39-48 years old, and 49-60 years old. Teaching experience was also divided into three groups: 0-10 years, 11-20 years, and 21-30 years. Professional development included two groups: teachers who had professional development and teachers who did not have professional development. The dependent variables were Awareness, Informational, Personal, Management, Consequence, Collaboration, and Refocusing.

Descriptive statistics (mean and standard deviation) were computed to examine participants' stages of concern about MALL. A one-way multivariate analysis of variance (MANOVA), using Wilks' Lambda $(\Lambda)$ with an alpha of .05, was conducted to test whether there was a significant difference among participants' stages of concern about MALL based on some selected demographic and technographic variables (gender, age, teaching experience, and professional development).

\section{RESUlts}

\section{A. Participants' Overall Stages of Concern (SoC)}

To examine participants' stages of concern about MALL, descriptive statistical analysis was computed (Figure 2) and results showed that the Informational stage was the highest stage of concern for participants, followed by the Personal stage as the second highest stage of concern, followed by the Management stage as the third highest stage of concern. The minimal stages of concern for participants were Consequence, Collaboration, Refocusing, and Awareness respectively.

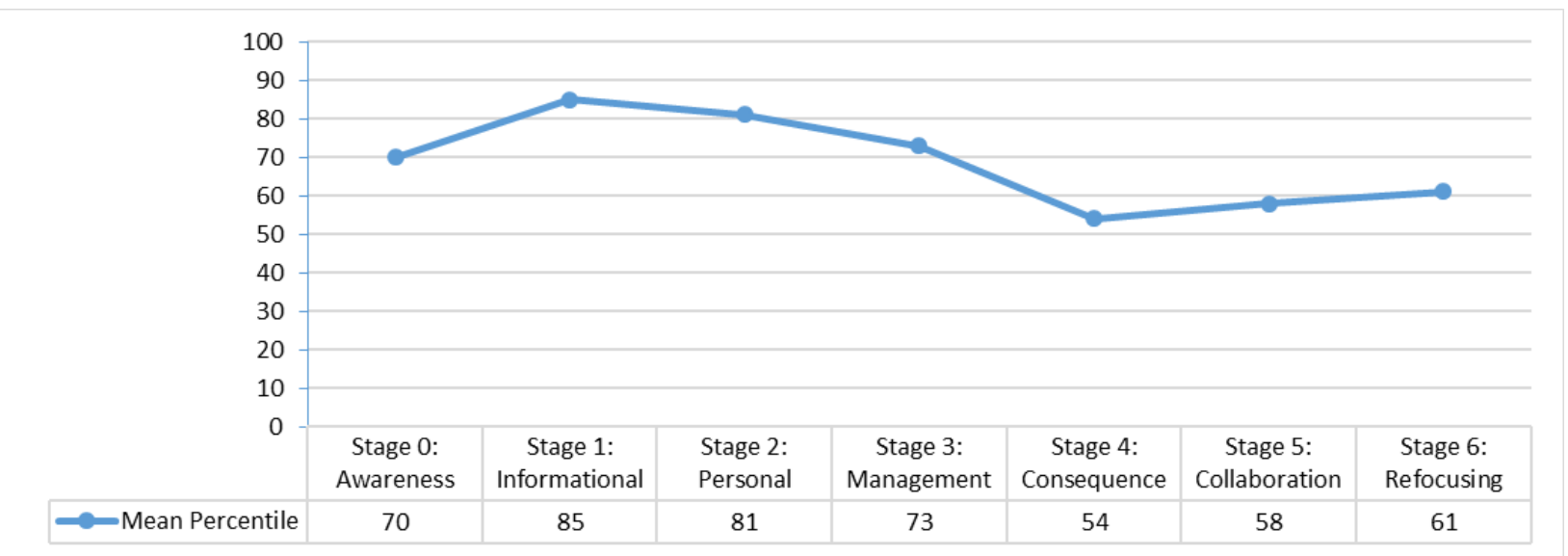

Figure 2. Profiles of Participants' Overall Stages of Concern about MALL

\section{B. Participants' Stages of Concern (SoC) Based on Gender}

Investigating the participants' stages of concern about MALL based on their gender (Figure 3) revealed that the male participants expressed higher concerns than female participants at the Informational, Personal, Collaboration, and Refocusing stages; while female participants showed higher concerns than male participants at the Awareness, Management, and Consequence stages. 


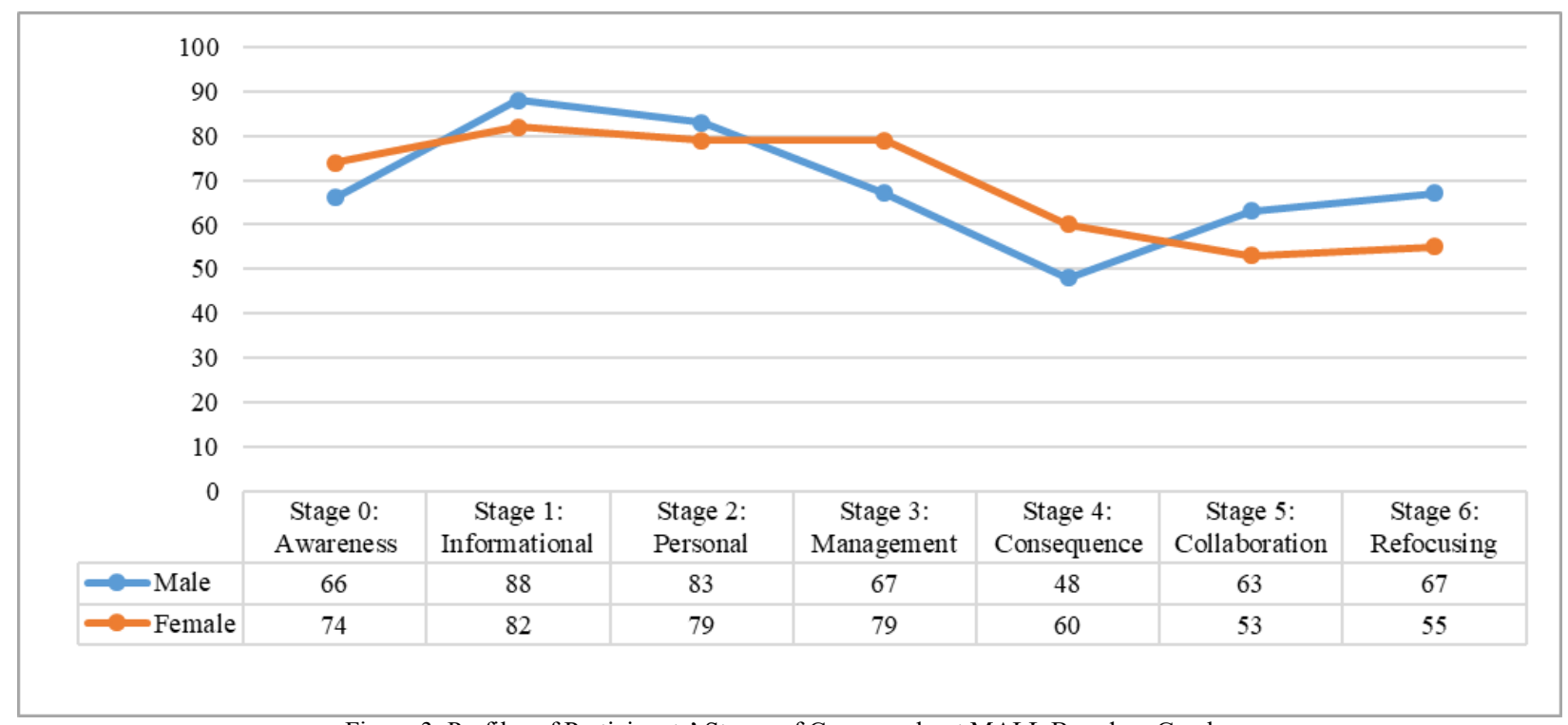

Figure 3. Profiles of Participants' Stages of Concern about MALL Based on Gender

A one-way MANOVA was conducted to analyze whether gender had any statistical significant effect on the participants' stages of concern about MALL. The MANOVA results (Table 2) revealed that there was no statistically significant difference in teachers' concerns based on their gender, $F(7,114)=1.055, p=0.397$, Wilks' $\Lambda=0.939$. Because the MANOVA test was not statistically significant, there was no need to conduct ANOVA test on each stage of concern.

TABLE 2

MANOVA TESTS FOR GENDER

\begin{tabular}{llllll}
\hline Effect & Wilks' $\boldsymbol{\Lambda}$ & $\mathbf{F}$ & Hypothesis df & Error df & P \\
\hline Gender & 0.939 & 1.055 & 7 & 114 & 0.397 \\
\hline
\end{tabular}

\section{Participants' Stages of Concern (SoC) Based on Age}

Analyzing the participants' stages of concern about MALL based on their age (Figure 4) indicated that they all shared the same concerns scoring high on the Informational, Personal, and Management stages; while scoring low on the Awareness, Collaboration, Refocusing, and Consequences stages. However, the profile of the age group (49-60 years old) expressed higher concerns than the other two groups. In contrast, the profile of the age group (20-38 years old) showed lower concerns than the other two groups.

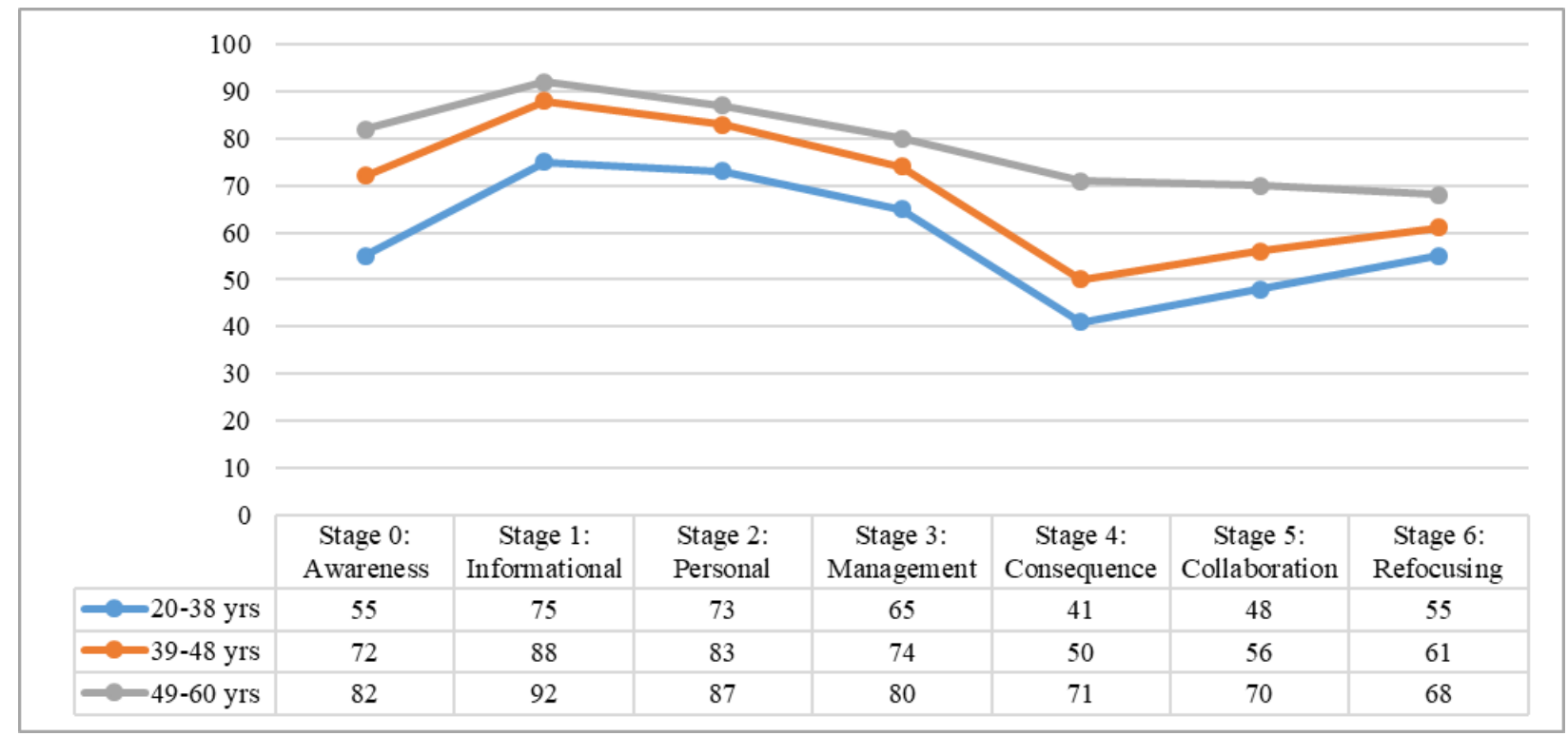

Figure 4. Profiles of Participants' Stages of Concern about MALL Based on Age

A one-way MANOVA was conducted to scrutinize whether age had any statistical significant effect on the participants' stages of concern about MALL. The MANOVA results (Table 3) revealed that there was no statistically 
significant difference in teachers' concerns based on their age, $F(14,228)=1.592, p=0.145$, Wilks' $\Lambda=0.950$. Because the MANOVA test was not statistically significant, there was no need to conduct ANOVA test on each stage of concern.

TABLE 3

MANOVA TESTS FOR AGE

\begin{tabular}{llllll}
\hline Effect & Wilks' $\boldsymbol{\Lambda}$ & $\boldsymbol{F}$ & Hypothesis $\boldsymbol{d}$ f & Error $\boldsymbol{d f}$ & $\boldsymbol{P}$ \\
\hline Age & 0.950 & 1.592 & 14 & 228 & 0.145 \\
\hline
\end{tabular}

\section{Participants' Stages of Concern (SoC) Based on Teaching Experience}

Exploring the participants' stages of concern about MALL based on their teaching experience (Figure 5) showed that they had varying concerns. The participants who had (0-10) years of teaching experience showed highest concerns at the Informational stage and lowest concerns at the Consequence stage; whereas, the participants who had (21-30) years of teaching experience had the highest concerns at the Personal stage and the lowest concerns at the Refocusing stage.

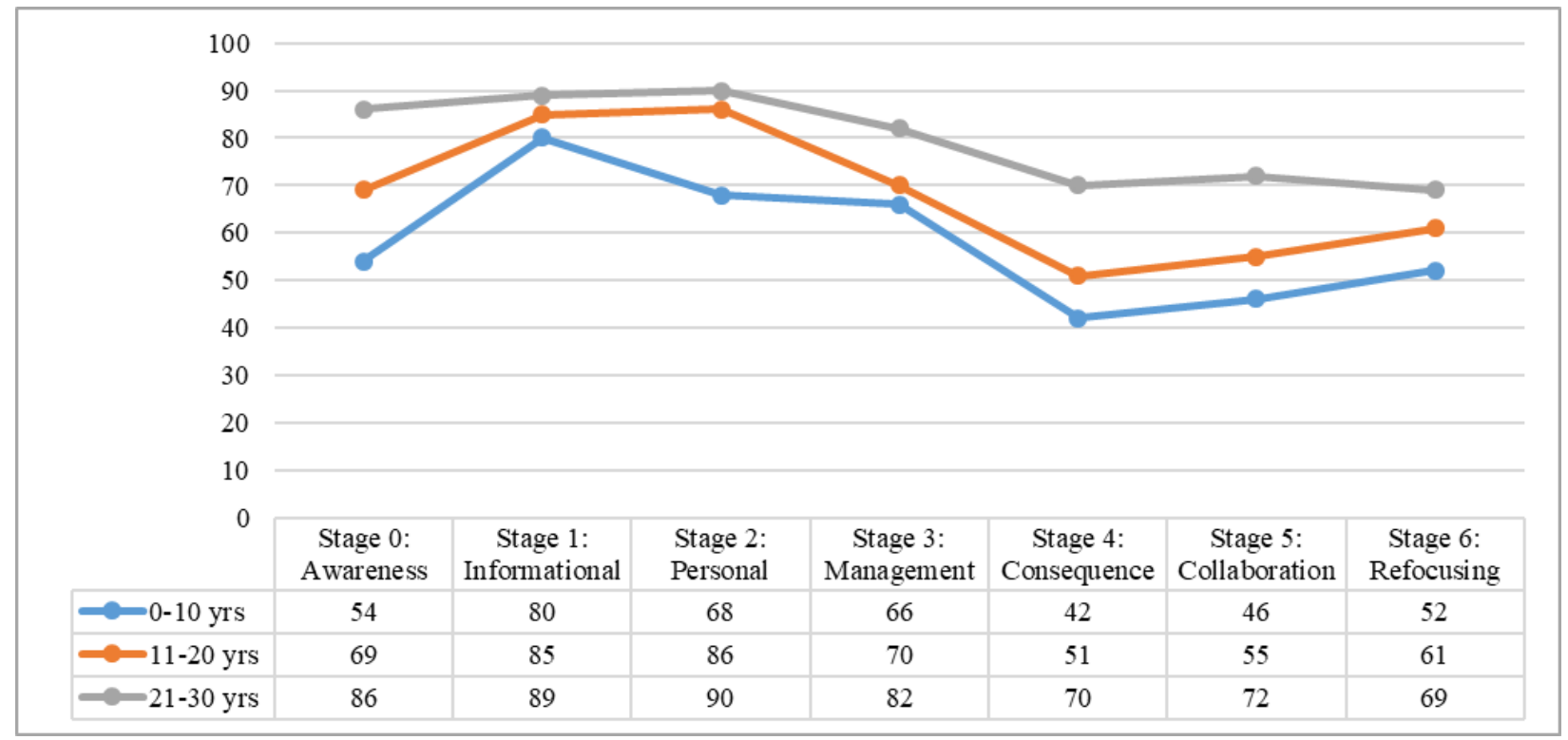

Figure 5. Profiles of Participants' Stages of Concern about MALL Based on Teaching Experience

A one-way MANOVA was conducted to investigate whether teaching experience had any statistical significant effect on the participants' stages of concern about MALL. The MANOVA results (Table 4) revealed that there was no statistically significant difference in teachers' concerns based on their teaching experience, $\mathrm{F}(14,228)=1.252, \mathrm{p}=$ 0.197 , Wilks' $\Lambda=0.902$. Because the MANOVA test was not statistically significant, there was no need to conduct ANOVA test on each stage of concern.

TABLE 4

MANOVA TESTS FOR TEACHING EXPERIENCE

\begin{tabular}{llllll}
\hline Effect & Wilks' $^{\prime} \boldsymbol{\Lambda}$ & $\boldsymbol{F}$ & Hypothesis $\boldsymbol{d f}$ & Error $\boldsymbol{d f}$ & $\boldsymbol{P}$ \\
\hline $\begin{array}{l}\text { Teaching } \\
\text { Experience }\end{array}$ & 0.902 & 1.252 & 14 & 228 & 0.197 \\
\hline
\end{tabular}

\section{E. Participants Stages of Concern (SoC) Based on Professional Development (PD)}

Examining the participants' stages of concern about MALL based on their professional development (Figure 6) indicated that the participants who had no previous PD expressed higher concerns than the participants who had previous PD at the Awareness, Informational, Personal, Management, and Consequence stages; whereas, participants with previous PD showed higher concerns than their counterparts at the Collaboration and Refocusing stages. 


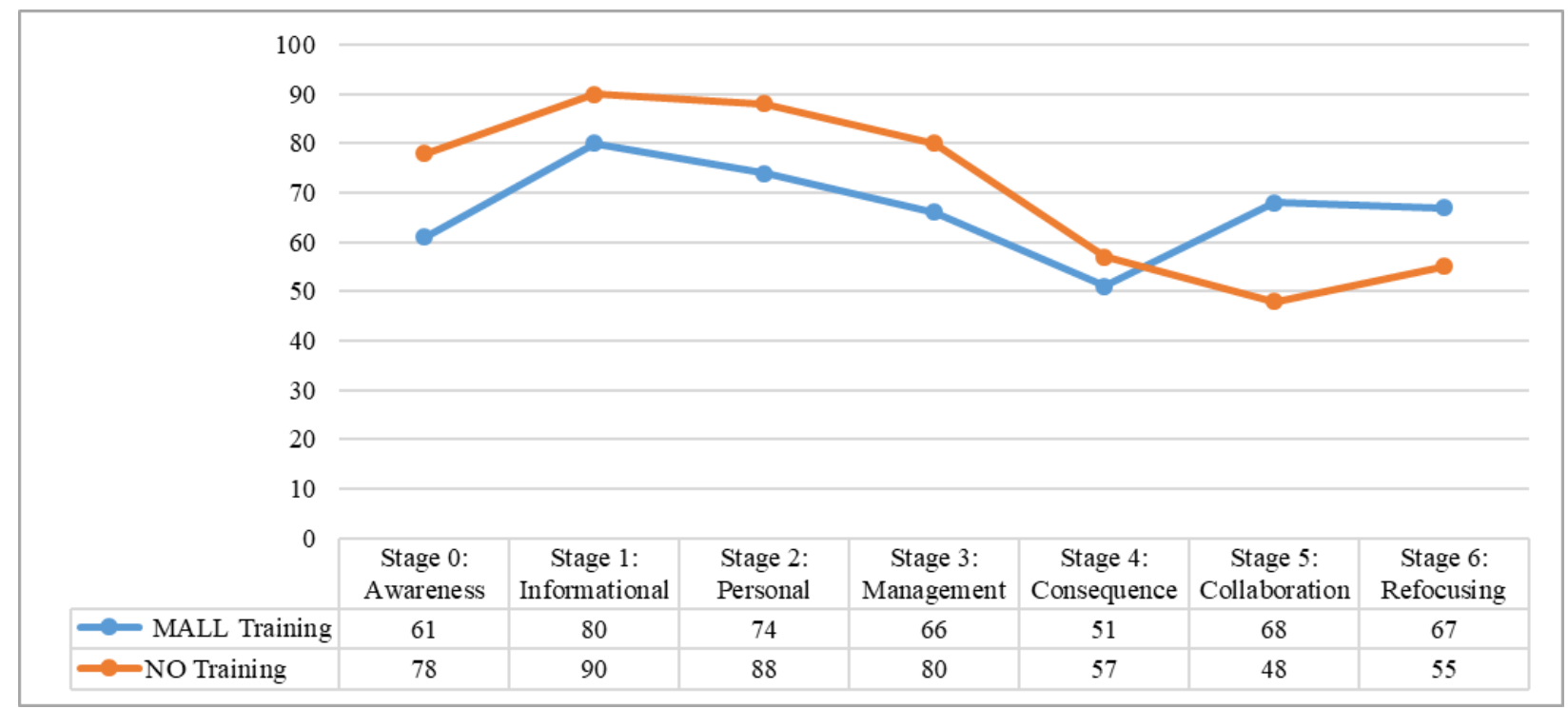

Figure 6. Profiles of Participants' Stages of Concern about MALL Based on Professional Development

A one-way MANOVA was conducted to examine whether professional development had any statistical significant effect on the participants' stages of concern about MALL. The MANOVA results (Table 5) revealed that there was a statistically significant difference in teachers' concerns based on their professional development, $F(7,114)=3.601, p=$ 0.001 , Wilks' $\Lambda=0.924$.

TABLE 5

MANOVA TESTS FOR PROFESSIONAL DEVELOPMENT

\begin{tabular}{llllll}
\hline Effect & Wilks $^{\prime} \boldsymbol{\Lambda}$ & $\boldsymbol{F}$ & Hypothesis $\boldsymbol{d f}$ & Error $\boldsymbol{d f}$ & $\boldsymbol{P}$ \\
\hline $\begin{array}{l}\text { Professional } \\
\text { Development }\end{array}$ & 0.924 & 3.601 & 7 & 114 & 0.001 \\
\hline
\end{tabular}

Because the MANOVA test was statistically significant, the ANOVA test was conducted on each stage of concern. The ANOVA results (Table 6) showed that there was a significant difference in five stages of concern between those who had professional development and those who did not have any previous PD, namely, Stage 1: Informational ( $\mathrm{p}$ $=.001)$, Stage 2: Personal $(\mathrm{p}=.003)$, Stage 3: Management $(\mathrm{p}=.007)$, Stage 4: Consequence $(\mathrm{p}=.03)$, and Stage 5: Collaboration $(\mathrm{p}=.04)$.

TABLE 6

ANOVA TEST FOR PROFESSIONAL DEVELOPMENT

\begin{tabular}{lllllll}
\hline Stage of Concern & Type III SS & $\boldsymbol{d f}$ & Mean Square & $\boldsymbol{F}$ & $\boldsymbol{P}$ \\
\hline $\begin{array}{l}\text { Stage } \\
\text { Unconcerned }\end{array}$ & $0:$ & 432.740 & 1 & 432.740 & 8.11 & .148 \\
\hline $\begin{array}{l}\text { Stage } \\
\text { Informational }\end{array}$ & $1:$ & 250.20 & 1 & 250.20 & 4.51 & .001 \\
\hline Stage 2: Personal & 292.89 & 1 & 292.89 & 7.45 & .003 \\
\hline $\begin{array}{l}\text { Stage } \\
\text { Management }\end{array}$ & $3:$ & 170.62 & 1 & 170.62 & 3.44 & .007 \\
\hline $\begin{array}{l}\text { Stage } \\
\text { Consequence }\end{array}$ & $4:$ & 320.634 & 1 & 320.634 & 4.88 & .03 \\
\hline $\begin{array}{l}\text { Stage } \\
\text { Collaboration }\end{array}$ & $5:$ & 168.014 & 1 & 168.014 & 3.36 & .04 \\
\hline \begin{tabular}{l} 
Stage 6: Refocusing \\
\hline
\end{tabular} & 443.583 & 1 & 443.583 & 2.21 & .08 \\
\hline
\end{tabular}

\section{DISCUSSION}

This study investigated Saudi EFL teachers' concerns about the adoption of Mobile Assisted Language Learning (MALL). The study also examined whether some specific demographic and technographic variables (gender, age, teaching experience, and professional development) had any statistically significant effect on EFL teachers' stages of concern about MALL.

The results of this study showed that the participants expressed high concerns at the Informational, Personal, and Management stages regarding the adoption of MALL. On the other hand, the participants reported minimal concerns at the Awareness, Refocusing, Collaboration, and Consequence stages. These results follow the same typical nonuser SoC profile scoring highest on stages 0,1 , and 2 and lowest on stages 4, 5, and 6 (George et al., 2006). 
The statistical analysis revealed that the male participants expressed higher concerns at the Informational, Personal, Collaboration, and Refocusing stages; while the female participants showed higher concerns at the Awareness, Management, and Consequence stages. The results also showed that the participants from all of the three age groups shared the same concerns scoring high at the Informational, Personal, and Management stages; while scoring low at the Awareness, Collaboration, Refocusing, and Consequences stages. The findings also reported that the participants who had (0-10) years of teaching experience showed high concerns at the Informational stage and minimal concerns at the Consequence stage; whereas, the participants who had (21-30) years of teaching experience had the highest concerns at the Personal stage and the lowest concerns at the Refocusing stage. The analysis of professional development (PD) revealed that the participants who had no previous PD expressed high concerns at the Awareness, Informational, Personal, Management, and Consequence stages; while the participants who had previous PD showed minimal concerns at the Collaboration and Refocusing stages.

The MANOVA analysis revealed no significant difference among the participants in terms of their concerns about MALL based on their gender, age, and teaching experience. Such findings indicate that Saudi EFL teachers' gender, age, and teaching experience have no effect on their concerns about using and implementing MALL. These findings are consistent with previous studies which reported that gender, age, and teaching experience did not impact teachers' SoCs and were not significant predictors of technology adoption. George et al. (2006) asserted that gender, age, and teaching experience were not predictive of the participants' stages of concern (SoC); therefore, they recommended exploring other critical variables associated with the innovation adoption. Ball (2014) studied faculty's concerns towards implementing mobile technology devices in the classroom and found that their concerns were not influenced by their gender, age, and years of teaching experience. Examining the relationship between full-time faculty's age and gender and their concerns in adopting online learning, Hwu (2011) reported no significant difference between gender, age and faculty's concerns. Yeldell (2017) studied the stages of concern for teachers with the innovating of digital one-to-one and found that teachers' gender and age did not impact their SoC.

The MANOVA analysis also yielded a significant difference among the participants in terms of their stages of concerns about MALL based on their professional development. These results entail that Saudi EFL teachers' professional development has a significant effect on their concerns about MALL. These results are in line with other studies which found a significant difference between the participants' stages of concerns and their professional development. Hall and Hord (2001) concluded that professional development is more likely predictive of concerns than age, gender, and teaching experience. Professional development (i.e., technology training) was frequently reported to have a significant effect on reducing teachers' self-concerns about technology adoption (Adams, 2002; Atkins \& Vasue 2000; Casey \& Rakes, 2014; Dobbs, 2000; Pathebridge, 2007). Three important SoC studies, which were conducted on Saudi public universities, also support the findings of the current study pertaining to the impact of professional development on users' concerns. Al-Sarrani (2010) studied faculty's concerns about the adoption of blended learning at Taibah University, Kamal (2013) investigated the faculty's concerns about the adoption of online teaching at King Abdulaziz University, and Omar (2016) examined faculty's concerns about the adoption of online teaching at King Saud University. The three studies found a significant effect of professional development on the use of technology in teaching.

These findings suggest that Saudi EFL teachers are at their self-concern stage. They are aware of and interested in MALL, but they need more information about utilizing and implementing MALL in their teaching. They are more concerned about how MALL affects them and how MALL would benefit them at the personal level. They have high concerns about organizing, managing, and scheduling MALL. They would like to understand the instructional use of MALL, realize the ways in which MALL could be used for ESL purposes, and identify the available resources if they decide to adopt MALL in their teaching. They seek more information on how using MALL is better than their current teaching practices and how their role will change when they adopt MALL. They want to know how to meet the demands of adopting MALL, how to resolve conflicts with existing teaching practices and policies, and how much time and energy are required if they start using MALL. On the other hand, the findings confirm that Saudi EFL teachers have minimal concerns for the impact of MALL on their students as well as their students' attitudes toward MALL. They are not worried about coordinating and cooperating with others regarding the use of MALL and they are not keen to know what other teachers doing when using MALL. Besides, they do not seek other approaches or alternatives that they think might work better. Factors such as gender, age, and teaching experience were not predictive of Saudi EFL teachers' MALL adoption. Those factors had no statistically significant effect on the teachers' concerns about using and implementing MALL in their teaching process. However, professional development was a significant predictor of MALL adoption among Saudi EFL teachers. The more professional development teachers have, the less self-concerns they have about MALL adoption. Technology training could help decrease teachers' self-concerns and increase their impact-concerns, which eventually leads to full adoption of MALL. These findings indicate that more attention should be given to professional development and that technology training should be a priority for a successful and effective MALL adoption in EFL classrooms.

\section{CONCLUSION}

Several studies investigated the predictors of technology adoption and asserted the importance of professional 
development in adopting, and implementing technology innovations into the learning and teaching process. The findings of this study emphasized the vital role of technology-related professional development in adopting and implementing mobile assisted language learning. Technology-related professional development, as described by Pathebridge (2007), may include workshops, seminars, programs, and conferences which develop knowledge and enhance skills in integrating technology innovations into the learning and teaching process. Increasing professional development opportunities and providing successful hands-on experiences concerning mobile assisted language learning may alleviate teachers' self-concerns and encourage them to fully adopt MALL in their teaching process. Professional development activities cannot be designed without an understanding of teachers' concerns and technology could only be fully integrated into teaching if teachers are provided enough hours of training (Pathebridge, 2007).

To achieve successful adoption of MALL, policy makers, educators, and EFL professionals/teachers should take into account the six assumptions which were proposed by Hord et al. (1987, p. 5-6) for adopting innovations in general:

1. Change is a process not an event; it takes time.

2. Change is accomplished by individuals; individuals must be the focus of attention.

3. Change is a personal experience; individuals are different and act differently to change.

4. Change involves development growth; individuals express feelings and skills as they go through different stages.

5. Change is understood in operational terms; individuals relate to change and how it affects their current practice.

6. The focus of facilitation should be on individuals, innovations, and the context; the real meaning of change lies in its human, not material, component.

It is worth mentioning that effective adoption of innovations requires not only addressing teachers' concerns but also providing appropriate interventions (Hord et al., 1987). It could be concluded that teachers should be involved in discussions and decisions about MALL and its implementation and unaware teachers should be encouraged to talk with their colleagues who know about MALL (awareness). EFL teachers should also have clear and accurate information about MALL and how it relates to their current practices (informational). In addition, the personal concerns of teachers about MALL adoption should be communicated, channeled, and legitimized (personal) and all the technical requirements and support of MALL should be addressed to the teachers before, during, and after the adoption process (management). Besides, teachers should be provided with opportunities to visit other classroom settings where MALL is implemented (consequence) and should be provided with opportunities to develop those skills necessary for working collaboratively (collaboration). Last but not least, teachers should be encouraged to channel their ideas about MALL in ways that will be productive (refocusing).

The results of this study could be used to guide future research into EFL teachers' concerns about mobile assisted language learning. The findings of the current study would also suggest a need for investigating other factors that might be predictive of teachers' concerns about MALL such as technical support, institutional support, course level, class size, and socio-cultural differences. A future study that includes EFL teachers at private and international schools in Saudi Arabia might also yield interesting findings.

\section{REFERENCES}

[1] Adams, N. B. (2002). Educational computing concerns of postsecondary faculty. Journal of Research on Technology in Education, 34(3), 285 - 303. https://doi.org/10.1080/15391523.2002.10782350.

[2] Alemi, M., Sarab, M., \& Lari, Z. (2012). Successful learning of academic word list via MALL: Mobile Assisted Language Learning. International Education Studies, 5(6), 99-109. https://doi.org/10.5539/ies.v5n6p99.

[3] Al-Sarrani, N. (2010). Concerns and professional development needs of science faculty at Taibah University in adopting blended learning (Publication No. 3408101) [Doctoral dissertation, Kansas State University]. ProQuest Dissertations and Theses Global.

[4] Amer, M. (2010). Idiomobile for learners of English: A study of learners' usage of a mobile learning application for learning idioms and collocations (Publication No. 3413155) [Doctoral dissertation, Indiana University of Pennsylvania]. ProQuest Dissertations and Theses Global.

[5] Anaraki, F. (2009). A Flash-based mobile learning system for learning English as a second language. Proceedings International Conference on Computer Engineering and Technology. Singapore (pp. 400-404). https://doi.org/10.1109/ICCET.2009.183.

[6] Atkins, N. E., \& Vasu, E. S. (2000). Measuring knowledge of technology usage and stages of concern about computing: A study of middle school teachers. Journal of Technology and Teacher Education, 8(4), 279 - 302.

[7] Ball, M. (2014). Faculty concerns toward implementing mobile technology devices in the higher education classroom (Publication No. 3643397) [Doctoral dissertation, Walden University]. ProQuest Dissertations and Theses Global.

[8] Basak, S. K., Wotto, M., \& Belanger, P. (2018). E-learning, M-learning, and D-learning: Conceptual definition and comparative analysis. E-Learning Digital Media, 15(4), 191-216. https://doi.org/10.1177/2042753018785180.

[9] Behera, S. K. (2013). E- and M-learning: A Comparative Study. International Journal on New Trends in Education and Their Implications, 4(3), $65-78$.

[10] Casey, H. B., \& Rakes, G. (2014). An Analysis of the Influence of Technology Training on Teacher Stages of Concern Regarding the Use of Instructional Technology in Schools. Journal of Computing in Teacher Education, 18(4), $124-132$. https://doi.org/10.1080/10402454.2002.10784448.

[11] Chang, C-K., \& Hsu, C-K. (2011). A mobile-assisted synchronously collaborative translation-annotation system for English as a foreign language (EFL) reading comprehension. Computer Assisted Language Learning, 24(2), 155-180. 
https://doi.org/10.1080/09588221.2010.536952.

[12] Chen, K. T-C. (2017). Examining EFL instructors' and students' perceptions and acceptance toward M-Learning in Higher Education. Universal Access in the Information Society, 16, (4), 967-976. https://doi.org/10.1007/s10209-016-0494-8.

[13] Dobbs, R. L. G. (2000). Effects of training in a distance education telecommunications system upon the stages of concern of college faculty and administrators (Publication No. 9980142) [Doctoral dissertation, Texas A\&M University]. ProQuest Dissertations and Theses Global.

[14] Demouy, V., \& Kukulska-Hulme, A. (2010). On the spot: Using mobile devices for listening and speaking practice on a French language program. Open Learning: The Journal of Open and Distance Learning, 25(3), $217-232$. https://doi.org/10.1080/02680513.2010.511955.

[15] El-Hussein, M. O. M., \& Cronje, J. C. (2010). Defining Mobile Learning in the Higher Education Landscape. Educational Technology \& Society, 13 (3), 12-21.

[16] Facer, B., Abdous, M., \& Camarena, M. (2009). The Impact of Academic Podcasting on Students: Learning Outcomes and Study Habits. In R. de Cassia Veiga Marriott \& P. Lupion Torres (Eds.) Handbook of research on e-learning methodologies for language acquisition. Hershey, PA: Information Science Reference.

[17] George, A. A., Hall, G. E., \& Stiegelbauer, S. M. (2006). Measuring implementation in schools: The Stages of Concern Questionnaire. Austin, TX: SEDL. http://www.sedl.org/pubs/catalog/items/cbam17.html (accessed 11/4/2020).

[18] Goktalay, S. B. (2013). Challenges facing higher education: faculty's concerns about technologies of social media. International Journal of Continuing Engineering Education and Life-Long Learning, 23(1), 67-90.

[19] Hall, G. E., \& Hord, S. M. (1987). Change in schools: Facilitating the process. Albany, NY: State University of New York Press.

[20] Hall, G. E., \& Hord, S. M. (2001). Implementing change: Patterns, Principles, and potholes. Boston: Allyn and Bacon.

[21] Hall, G., Wallace, R., \& Dossett, W. (1973). A developmental conception of the adoption process within educational institutions. Austin, TX: The University of Texas.

[22] Hord, S. M., Rutherford, W. L., Huling-Austin, L., \& Hall, G. E. (1987). Taking charge of change. Alexandria, VA: Association of Supervision and Curriculum Development.

[23] Hwu, S. (2011). Concerns and professional development needs of university faculty in adopting online learning (Publication No. 3493794) [Doctoral dissertation, Kansas State University]. ProQuest Dissertations and Theses Global.

[24] Kamal, B. (2013). Concerns and professional development needs of faculty at King Abdul-Aziz University in Saudi Arabia in adopting online teaching (Publication No. 3563006) [Doctoral dissertation, Kansas State University]. ProQuest Dissertations and Theses Global.

[25] Kim, I. S. (2012). The Impact of M-Learning: Smart Phones/Tablet PCs and Their Potential Use for Foreign Language Learning. Language Learning Technologies, 2(1), 61-89.

[26] Korucu, A. T. \& Alkan, A. (2011). Differences between M-Learning (mobile Learning) and E-Learning, Basic Terminology and Usage of M-Learning in Education. Procedia - Social and Behavioral Sciences, 15, $1925-1930$. https://doi.org/10.1016/j.sbspro.2011.04.029.

[27] Kukulska-Hulme, A. \& Shield, L. (2008). An overview of mobile assisted language learning: from content delivery to supported collaboration and interaction. ReCALL, 20(3), 271-289. https://doi.org/10.1017/S0958344008000335.

[28] Lan, Y.J., Sung, Y.T., \& Chang, K.E. (2007). A mobile-device-supported peer-assisted learning system for collaborative early EFL reading. Language Learning and Technology, 11(3), 130-151.

[29] Norris, C. A., \& Soloway, E. (2011). Learning and schooling in the age of mobilism. Educational Technology, 51(6), 3-10.

[30] Omar, S. (2016). Concerns and professional development needs of faculty at King Saud University in Saudi Arabia in adopting online teaching (Publication No. 10161510) [Doctoral dissertation, Kansas State University]. ProQuest Dissertations and Theses Global.

[31] Ozuorcun, N. C. \& Tabak, F. (2012). Is M-Learning versus E-Learning or are they Supporting Each Other? Procedia - Social and Behavioral Sciences, 46, 299-305. https://doi.org/10.1016/j.sbspro.2012.05.110.

[32] Petherbridge, D. T. (2007). A concerns-based approach to the adoption of Web-based learning management systems (Publication No. 3269445) [Doctoral dissertation, North Carolina State University]. ProQuest Dissertations and Theses Global.

[33] Prensky, M. (2001). Digital natives, digital immigrants. On the Horizon, 9(5), 1-6. https://doi.org/10.1108/10748120110424816.

[34] Schoepp, K. (2002). EFL teachers' technological use, concerns, and perceived barriers toward technology integration: A research proposal. EFL Teachers and Technology http://citeseerx.ist.psu.edu/viewdoc/download?doi=10.1.1.92.6085\&rep=rep1\&type=pdf (accessed 13/4/2020).

[35] SEDL. (n.d.). The Three Diagnostic Dimensions of the Concerns-Based Adoption Model (CBAM). http://www.sedl.org/cbam (accessed 9/5/2020).

[36] Straub, E. T. (2009). Understanding technology adoption: Theory and future directions for informal learning. Review of Educational Research, 79(2), 625-649. https://doi.org/10.3102/0034654308325896.

[37] Traxler, J. (2005). Defining mobile learning. Proceedings IADIS International Conference Mobile Learning, 261-266.

[38] Valarmathi, K. E. (2011). Mobile assisted language learning. Journal of Technology for ELT, 1(2). https://sites.google.com/site/journaloftechnologyforelt/archive/april2011/mobileassistedlanguagelearning (accessed 15/5/2020).

[39] Walsh, C., \& Shaheen, R. (2013). English in action (EIA): Mobile phones as an agent of change for large-scale teacher professional development and English language learning in Bangladesh. Paper presented at American Educational Association Annual Meeting, San Francisco, CA.

[40] Watkins, J. L. (2014). A Study of Individual Teacher's Instructional Technology Stages of Concern in Relationship to Levels of Instructional Integration in the One-to-one Learning Environment (Publication No. 10169523) [Doctoral dissertation, William Woods University]. ProQuest Dissertations and Theses Global.

[41] Yedla, S. (2013). MALL (Mobile Assisted Language Learning): A Paradise for English Language Learners. International Journal of English Language \& Translation Studies, 1(2), 91-99.

[42] Yeldell, A. (2017). Digital one-to-one implementation: The teachers' concerns in the change process (Publication No. 
10603695) [Doctoral dissertation, University of Alabama]. ProQuest Dissertations and Theses Global.

[43] Zurita, G. \& Nussbaum, M. (2004). A constructivist mobile learning environment supported by a wireless handheld network. Journal of Computer Assisted Learning, 20(4), 235-243. https://doi.org/10.1111/j.1365-2729.2004.00089.x.

Sulaiman Alnujaidi received his PhD degree in TEFL from the University of Kansas, USA in 2008. He is currently an Assistant Professor at the Department of English, College of Languages and Translation, Imam Muhammad Ibn Saud University (IMISU), Riyadh, Saudi Arabia. He teaches both English for General Purpose (EGP) and English for Specific Purpose (ESP). His research interests include EFL Learning Strategies, EFL Teaching Methods, Computer-Assisted Language Learning (CALL), \& MobileAssisted Language Learning (MALL). 